\title{
Integrating VIKOR with DEA for Efficiency Performance Measurement
}

\author{
Hsin-Pin Fu \\ Department of Marketing and Distribution Management, National Kaohsiung First University of Science and Technology, \\ Kaohsiung (811), Taiwan, ROC. \\ hpfu@nkfust.edu.tw
}

\begin{abstract}
The present study transferred the raw data of DEA to five performance criteria and utilized the VlseKriterijumska Optimizacija I Kompromisno Resenje (VIKOR) methodology to produce $S_{j}, R_{j}$, and $Q_{j}$, where $S_{j}$ and $R_{j}$ represent the utility measure and the regret measure, respectively and $Q_{j}$ represents the $i^{\text {th }}$ alternative VIKOR value. The output variables are replaced by $S_{j}, R_{j}$, and $Q_{j}$ and running DEA again (so-called 'VIKOR-DEA') to produce a more reliable efficiency value. A chain of fast food stores was chosen as the sample on which to test the performance of the proposed VIKOR-DEA model. The results of the study verify the VIKOR-DEA analytical method as a more reliable measure of efficiency for the chain stores than the DEA method.

Index Terms - performance measurement, DEA, VIKOR.
\end{abstract}

\section{Introduction}

If the data used in DEA are subject to statistical deviation, or if multiple decision-making units (DMUs) are analyzed, management and observational errors will occur. This can cause the output efficiency frontier to be distorted (Wang, 2003). In addition, selection of an appropriate DEA model is sometimes problematic. Even though the choice of input and output variables is unrestricted in DEA, the estimated efficiency for a DMU depends on the number of inputs plus outputs. The greater the number of variables included, the lower the level of discrimination ( $\mathrm{Fu}$ and $\mathrm{Ou}, 2012$ ). The discrimination capability of DEA is thus relatively weak in terms of performance measurement. To improve this shortcoming, the present study aims to improve the application of DEA in an efficiency analysis of chain stores by utilizing a tool based on performance criteria; that is, using the VIKOR methodology as an auxiliary tool in combination with DEA to produce a more reliable efficiency frontier and thus correct any deviation that might occur when using DEA. This can enhance the discrimination capability when DEA is used in the performance measurement. Empirical analysis of the efficiency of a chain of fast food stores is then undertaken to compare the results obtained from each of the methods ('VIKOR-DEA' and 'DEA').

\section{Methodology}

DEA models can be of two types: (i) output-based models, in which the aim is the maximization of output under conditions of constant input; and (ii) input-based models, in which the aim is minimization of input under conditions of constant output. The choice between an input-based model and an output-based one is determined by market conditions. An output-based model is desirable in a competitive market in which input is manipulated by the DMU; conversely, an inputbased model is preferable in a monopolized market (Barros and Alves, 2003). In the present study, which investigated a chain of retail stores selling lifestyle accessories, the market was not monopolized. Therefore, the CCR output-based model (Charnes et al., 1978) and the BCC output-based model (Banker et al., 1984) were adopted.

VIKOR was developed as an MCDM method for solving discrete decision problems that have non-commensurable and conflicting criteria. The VIKOR method, which focuses on ranking and selecting from a set of alternatives, provides compromise solutions for problems with conflicting criteria (Opricovic \& Tzeng, 2004). Such a 'compromise solution' is a feasible solution that is closest to the ideal solution after taking into account certain mutually agreed concessions. In providing such a compromise solution, VIKOR applies the concepts of 'acceptable advantage' and 'acceptable stability' to determine the maximum 'group utility of the majority' and the minimum 'individual regret of the opponent'. The negotiated compromise solution is thus likely to be perceived as acceptable by decision-makers.

\section{Research design and data collection}

A chain of 50 fast food stores located in Taipei city was chosen as the sample for data analysis in this study (Table 1). DEA SOLVER (Saitech, Inc.) which is a DEA analysis software, is used to run DEA, and a set of OE, TE and SE values are obtained. The results of the total efficiency analysis indicate that all stores in the chain were 'efficient' $(\mathrm{OE}=1)$ when using DEA alone. This paper found that the $\mathrm{OE}$ had been distorted, however, because the slack analysis table (Table 1) shows that some DMUs have characteristics which identify them as efficient, while some show room for improvement, and are thus inefficient DMUs. 
TABLE 1 Raw data for this study (unit: New Taiwan Dollar, NT\$)

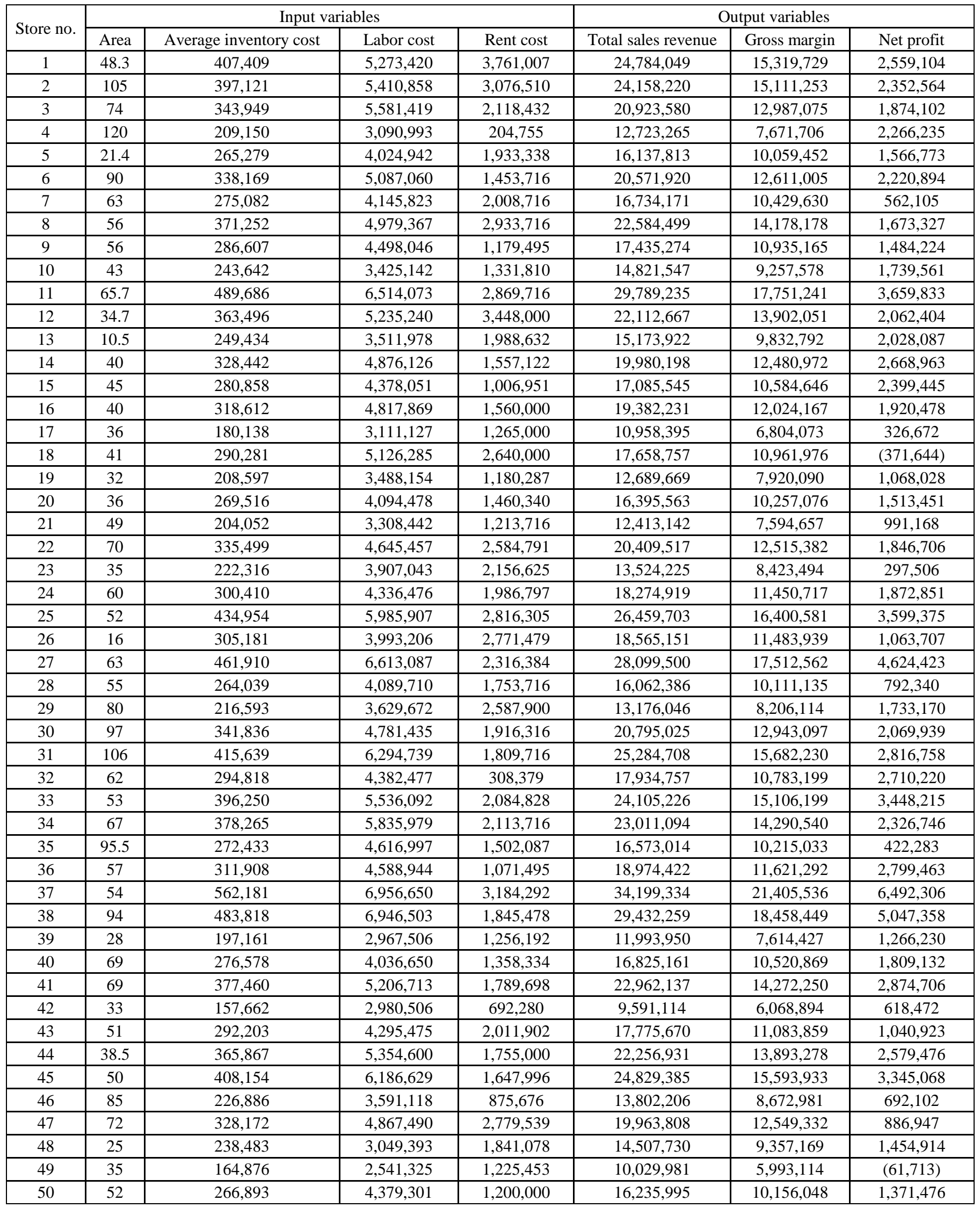


TABLE 2 OE, TE and SE of DEA and VIKOR-DEA

\begin{tabular}{|c|c|c|c|c|c|c|}
\hline \multirow{2}{*}{ DMU } & \multicolumn{2}{|c|}{ DEA } & \multicolumn{4}{|c|}{ VIKOR-DEA } \\
\hline & $\mathrm{OE}$ & $\mathrm{TE}$ & $\mathrm{OE}$ & $\mathrm{TE}$ & SE & RTS \\
\hline 1 & 1 & 0.8603023 & 0.7871402 & 0.8713744 & 0.903332 & Constant \\
\hline 2 & 1 & 0.8573665 & 0.7204309 & 0.8348875 & 0.862908 & Constant \\
\hline 3 & 1 & 0.7783611 & 0.7175111 & 0.8401244 & 0.854053 & Decreasing \\
\hline 4 & 1 & 1 & 1 & 1 & 1 & Constant \\
\hline 5 & 1 & 0.8864837 & 0.8417971 & 0.9184848 & 0.916506 & Decreasing \\
\hline 6 & 1 & 0.8745075 & 0.766134 & 0.872569 & 0.878021 & Decreasing \\
\hline 7 & 1 & 0.8048612 & 0.6462623 & 0.7688146 & 0.840596 & Decreasing \\
\hline 8 & 1 & 0.8690614 & 0.6969686 & 0.8086134 & 0.861931 & Constant \\
\hline 9 & 1 & 0.8672122 & 0.7806596 & 0.8675971 & 0.899795 & Constant \\
\hline 10 & 1 & 0.9577391 & 0.9402118 & 0.9622635 & 0.977084 & Constant \\
\hline 11 & 1 & 0.9166019 & 0.7930021 & 0.892307 & 0.88871 & Constant \\
\hline 12 & 1 & 0.8382324 & 0.7564524 & 0.8640076 & 0.875516 & Decreasing \\
\hline 13 & 1 & 1 & 1 & 1 & 1 & Constant \\
\hline 14 & 1 & 0.9112826 & 0.9124652 & 0.9661945 & 0.944391 & Decreasing \\
\hline 15 & 1 & 0.9072828 & 0.9645369 & 0.9873872 & 0.976858 & Constant \\
\hline 16 & 1 & 0.8875909 & 0.8046484 & 0.8921853 & 0.901885 & Decreasing \\
\hline 17 & 1 & 0.8035928 & 0.8825928 & 0.9030716 & 0.977323 & Constant \\
\hline 18 & 1 & 0.6808891 & 0.515496 & 0.6620115 & 0.778681 & Decreasing \\
\hline 19 & 1 & 0.8330359 & 0.8972394 & 0.9485733 & 0.945883 & Constant \\
\hline 20 & 1 & 0.8878631 & 0.8272852 & 0.9008189 & 0.91837 & Constant \\
\hline 21 & 1 & 0.832416 & 0.8808022 & 0.926749 & 0.950422 & Constant \\
\hline 22 & 1 & 0.8471474 & 0.7290602 & 0.8497243 & 0.857996 & Constant \\
\hline 23 & 1 & 0.6977144 & 0.7304134 & 0.8178646 & 0.893074 & Constant \\
\hline 24 & 1 & 0.8592541 & 0.7733826 & 0.8905436 & 0.868439 & Decreasing \\
\hline 25 & 1 & 0.8923533 & 0.8673624 & 0.9398043 & 0.922918 & Decreasing \\
\hline 26 & 1 & 1 & 0.7667356 & 0.8401213 & 0.912649 & Constant \\
\hline 27 & 1 & 0.9023631 & 0.9816262 & 1 & 0.981626 & Decreasing \\
\hline 28 & 1 & 0.8148466 & 0.6988289 & 0.8098131 & 0.862951 & Decreasing \\
\hline 29 & 1 & 0.6673814 & 0.9311225 & 0.9617623 & 0.968142 & Constant \\
\hline 30 & 1 & 0.8960359 & 0.7381218 & 0.8521789 & 0.866158 & Constant \\
\hline 31 & 1 & 0.8700757 & 0.7546893 & 0.855388 & 0.882277 & Constant \\
\hline 32 & 1 & 1 & 1 & 1 & 1 & Constant \\
\hline 33 & 1 & 0.9229253 & 0.9101406 & 0.9614242 & 0.946659 & Decreasing \\
\hline 34 & 1 & 0.8268642 & 0.7486387 & 0.8580282 & 0.872511 & Decreasing \\
\hline 35 & 1 & 0.7553736 & 0.6076657 & 0.7390182 & 0.822261 & Decreasing \\
\hline 36 & 1 & 0.9378042 & 0.9580787 & 0.9862393 & 0.971446 & Constant \\
\hline 37 & 1 & 1 & 1 & 1 & 1 & Constant \\
\hline 38 & 1 & 0.9371284 & 1 & 1 & 1 & Constant \\
\hline 39 & 1 & 1 & 1 & 1 & 1 & Constant \\
\hline 40 & 1 & 0.897465 & 0.8045979 & 0.9033127 & 0.890719 & Decreasing \\
\hline 41 & 1 & 0.9382782 & 0.8296903 & 0.9152824 & 0.906486 & Constant \\
\hline 42 & 1 & 0.8987728 & 1 & 1 & 1 & Constant \\
\hline 43 & 1 & 0.8442143 & 0.6863343 & 0.8124887 & 0.844731 & Decreasing \\
\hline 44 & 1 & 0.915185 & 0.8928897 & 0.9400478 & 0.949834 & Constant \\
\hline 45 & 1 & 0.893773 & 0.946336 & 0.9750074 & 0.970594 & Constant \\
\hline 46 & 1 & 0.8577791 & 0.7520122 & 0.8184129 & 0.918867 & Decreasing \\
\hline 47 & 1 & 0.7848421 & 0.6034697 & 0.7526162 & 0.801829 & Decreasing \\
\hline 48 & 1 & 1 & 1 & 1 & 1 & Constant \\
\hline 49 & 1 & 1 & 0.961879 & 1 & 0.961879 & Increasing \\
\hline 50 & 1 & 0.8303197 & 0.7965915 & 0.8775327 & 0.907763 & Constant \\
\hline
\end{tabular}


To address the above problem, VIKOR methodology are used to obtain a set of functions ( $S_{j}, R_{j}$, and $Q_{j}$ ). However, higher values for the performance criteria have a better performance in terms of the output values of DEA. Therefore, the output variables are replaced by $1-S_{j}, 1-R_{j}$, and $1-Q_{j}$, and DEA SOLVER is used to run the CCR model and BBC model again. Therefore, a set of new OE, TE and SE are obtained. The RTS, OE, TE and SE of 50 chain stores using the DEA method and VIKOR-DEA method, respectively, are shown in Table 2.

\section{Data Analysis}

This result indicated that the VIKOR-DEA method has more reliable discrimination capability than the DEA method. The important findings can be summarized as follows:

- The mean of OE was 0.832, the mean of TE was 0.9009, and the mean of SE was 0.9187 , which suggests that there remains room for improvement.

- $\quad$ Eight stores (stores 4, 13, 32, 37, 38, 39, 42, and 48) achieved a most productive scale size (MPS), and their RTS is constant.

- $\quad$ One store (store 49), which was at the stage of increasing RTS, had not achieved an MPS because it was efficient in TE but inefficient in SE. This suggests that, using the techniques at hand, expansion of the scale of this chain store would enhance their efficiency.

- 19 of the remaining 41 stores (stores 3, 5, 6, 7, 12, 14, $16,18,24,25,27,28,33,34,35,40,43,46$ and 47) had a decreasing RTS. The TE and SE of these stores could be enhanced by decreasing their input variables and their scale.

- $\quad$ The remaining 22 stores (stores 1, 2, 8, 9, 10, 11, 15, 17, $19,20,21,22,23,26,29,30,31,36,41,44,45$ and 50) were at a constant RTS. Their efficiency does not indicate a need to change their scale and input variables unless a major change occurs. No inputs or outputs increased or decreased, and maintenance of the scale is adequate.

\section{Conclusions}

The results obtained from the DEA and VIKOR-DEA models differ. The former assesses the efficiency of stores only as ostensibly efficient; as such, the technique is unable to rank the relative operational efficiency of efficient stores accurately. In contrast, by using VIKOR-DEA, the efficiency value of individual stores can be identified, thus enabling the chain to ascertain the differences between stores and hence rank them accurately. The results of this study demonstrate that VIKORDEA is an effective auxiliary tool for enhancing the discrimination capability of DEA. Although this paper verified that DEA in combination with VIKOR can provide a more reliable overall efficient value.

\section{Acknowledgment}

The authors thank the National Science Council (NSC) of the Executive Yuan, Taiwan, ROC for supporting this research (Research Grant No. NSC 102-2410-H-327-033-).

\section{References}

[1] S. Wang, "Adaptive non-parametric efficiency frontier analysis: a neuralnetwork-based model", Computers \& Operations Research, vol. 30, no.v2, pp. 279-295, 2003.

[2] H-P. Fu, and J-R. Ou, "Combining PCA with DEA to improve the evaluation of project performance data: A Taiwanese Bureau of Energy case study", Project Management Journal, vol. 44, no. 1, pp. 94-106, 2013

[3] C.P. Barros, and C.A. Alves, "Hypermarket retail store efficiency in Portugal", International Journal of Retail \& Distribution Management, vol..31, no. 11, pp. 549-560, 2003

[4] A. Charnes, W.W. Cooper and E. Rhodes, "Measuring the efficiency of decision making units", European Journal of Operational Research vol. 2, no. 6, pp. 429-444, 1978

[5] R. Banker, A. Charnes, and W.W. Cooper, "Some models for estimating technical and scale inefficiencies in data envelopment analysis", Management Science, vol. 30, no. 9, pp.1078-1092, 1984

[6] S. Opricovic, and G.H. Tzeng, "Compromise solution by MCDM methods: A comparative analysis of VIKOR and TOPSIS", European Journal of Operational Research, vol. 156, no. 2, pp. 445-455, 2004. 